\title{
Detecting Ionospheric TEC Disturbances by Three Methods of Detrending through Dense CORS During A Strong Thunderstorm
}

\author{
Mohamed Freeshah ${ }^{1,4,5}$, Xiaohong Zhang ${ }^{*, 2,3,4}$, Jun Chen ${ }^{2}$, Zhibo Zhao ${ }^{2}$, \\ Nahed Osama ${ }^{1}$, Mohammed Sadek ${ }^{5,6}$, Nana Twumasi ${ }^{1,7}$ \\ (1) State Key Laboratory of Information Engineering in Surveying, Mapping and Remote Sensing, Wuhan University, 129 \\ Luoyu Road, Wuhan 430079, China \\ (2) School of Geodesy and Geomatics, Wuhan University, 129 Luoyu Road, Wuhan 430079, China \\ (3) Key Laboratory of Geospace Environment and Geodesy, Ministry of Education, 129 Luoyu Road, Wuhan 430079, China \\ (4) Collaborative Innovation Center for Geospatial Technology, 129 Luoyu Road, Wuhan 430079, China \\ (5) Department of Surveying Engineering, Faculty of Engineering at Shoubra, Benha University, 108 Shoubra St., Cairo \\ 11629, Egypt \\ (6) School of Human Settlements and Civil Engineering, Xi'an Jiaotong University, Xi'an 710049, China \\ (7) Civil Engineering Department, Wa Polytechnic, Box 553, Wa, Upper West Region, Ghana
}

Article history: received October 15, 2019; accepted September 17, 2020

\begin{abstract}
Satellite navigation and communications system can substantially be disturbed by ionospheric perturbations. Consequently, monitoring ionospheric anomalous has great significance. In this study, we focus on the short-term irregular disturbances through a strong thunderstorm in Wuhan City, Hubei, China by using ground-based GNSS observations from dense Continuously Operating Reference Stations (CORS) with a sampling rate of $1 \mathrm{~s}$. The total electron content (TEC) was used to find possible perturbations after biases have been calibrated for the derived TEC. Additionally, the geomagnetic conditions and the state of solar radiation was checked in the study period to recognize the causes for the ionospheric disturbances. The maxima and minima values of TEC deviations were $\sim 2.5$ and 0.5 TECU, respectively. Three methods of Detrended Fluctuations Analysis (DFA) were applied to assess the ionospheric disturbances over GNSS CORS stations; "Multi-step numerical difference"(MSND), "6 6 th order polynomials fitting" (PF), and "one-week average difference"(AD). The analyzed results showed that MSND has the lowest performance. Meanwhile, the fitted TEC data with $6^{\text {th }}$ order polynomials technique presented an improvement and a discrepancy related to MSND. To resolve this discrepancy, we proposed $\mathrm{AD}$ technique, it accomplished the best performance related to the TEC disturbances and was compared with the other two techniques. The research findings showed that ionospheric disturbed electrons can be generated with various rates and different velocities through lightning influences.
\end{abstract}

Keywords: Ionosphere; Total Electron Content (TEC); Thunderstorm; Detrend; GNSS. 


\section{Mohamed Freeshah et al.}

\section{Introduction}

Reliable and fast knowledge about ionospheric variations has become increasingly important. GNSS users of single-frequency receivers need accurate corrections to remove signal degradation caused by the ionosphere. The ionospheric variations can be categorized as systematic and non-systematic. Systematic variations either takes place in cycles or does not. Consequently, it can be pre-modulated or predicted with reasonable accuracy [Rama Rao et al., 2006]. On the other hand, irregular variations which happen due to some phenomena such as earthquakes, tsunamis, and underground nuclear explosions (UNE) could not be expected [Amieri-Simkooei and Asgari, 2012; Jain, Vijay, and Gwal, 1996; Park et al., 2011; Salem et al., 2015; Savastano et al., 2017; Yu et al., 2015; Zhang and Tang, 2015]. There are many studies dealing with ionospheric disturbances which respond to the aforementioned hazards [Amieri-Simkooei and Asgari, 2012; Calais \& Minster, 1995; Jain et al., 1996; Park et al., 2011; Salem et al., 2015; Savastano et al., 2017; Yu et al., 2015; Zhang and Tang, 2015]. The common factor for these hazards is a unique epicenter, where we can obtain the epicenter and determine its starting time clearly according to the different research centers. In addition, it is a chance to focus on the coupling between the solid-Earth and atmosphere [Liu and Jin, 2019]. On the other side, ionospheric disturbances could be associated with lightning. However, it is quite difficult to deal with this issue where lightning has multi epicenters and different starting times.

Although the ionospheric anomalies have been observed through GPS TEC for about three decades [Calais and Minster, 1995], insufficient studies have been conducted on dealing with ionospheric response during lightning and their thunderstorm. With the increase of Continuously Operating Reference Station (CORS), it supplies not only abundant measurements to observe the pattern and evolution of ionospheric disturbances, but also a magnificent opportunity for studying more details about the coupling between the tropospheric activities and higher atmosphere. The electromagnetic fields produced by natural thundercloud activities energy can transfer from the troposphere mainly through wave activity, i.e., gravity waves (GWs) and infrasonic waves [Blanc, 1985; Chimonas, 1971; Sentman et al., 2003]. Therefore, the studies of ionospheric disturbances during lightning activity have been interested in exploring as well as monitoring the effect of this phenomenon through the ionosphere, where the lightning activity could disturb the TEC in the ionosphere. A statistical study was conducted on it in 2005 which found a relationship between lightning activity and the sporadic E layer intensification [Davis and Johnson, 2005]. During the lightning, the ionosphere was substantially disturbed by electrical activity, which can cause variations in electron density through heating the electrons [Layet al., 2013]. Consequently, Barta et al. [2013] have shown that the electron density of the sporadic E layer has decreased significantly associated with lightning based on infrared maps and lightning observations over the ionospheric station of Rome. On the other side, Lay et al. [2013] have fitted the GPS total electron content (TEC) data with a $6^{\text {th }}$ order polynomial, therefore, the variations are calculated by subtracting this fit from the data. So, anomalous TEC changes were closely associated with space and time to the large underlying thunderstorms. Similar to the method described above, 6 dual frequency GPS stations have been used with lightning data obtained from WorldWide Lightning Location Network (WWLLN) over southern Africa. The results have indicated that $~ 1$ TECU varied in TEC which corresponding to periods of lightning activity intensification in the studied regions [Amin, 2015]. However, fitting method acts more sensitive only for the higher-frequency variations. Additionally, it acts to filter out the lower-frequency changes [Lay et al., 2013].

Studying the response of the ionosphere to thunder provides a good way to understand the upper atmospheric coupling, where lightning or tropospheric activities may have transferred to the high atmosphere, and then cause ionospheric disturbances [Zhang and Tang, 2015]. It is well known that Detrending techniques is the most common method to analyze ionospheric disturbances. Park et al. [2011] used the "numerical difference method" to detect the ionospheric fluctuations using GPS observations. Afterward, [Zhang and Tang, 2015] presented a modified "numerical difference method" with multiple time steps to detect traveling ionospheric disturbances (TIDs) induced through UNE at North Korean by using GPS dual-frequency data. The effect of the time step is very relevant to the detectable period of the spectrum. The previous works have concluded that detrending methods may have a weakness for one or more of these reasons: (1) skips detectable disturbance, (2) time step could be relevant to the detectable period, (3) filter out lower-frequency variations [Park et al., 2011; Salem et al., 2015; X. Zhang and Tang, 2015]. It is worthy to indicate that we applied the first two detrending methods (1) Multi-step numerical difference (MSND) and (2) Six order polynomials fitting (PF), in order to assess the influence of thunderstorm activities on ionospheric perturbation through the local steady-state nighttime ionospheric over a small area by a dense GNSS 
CORS. The defects of the two detrending techniques have been confirmed through our research findings. For this reason, we have found the rationale to propose a third superior approach "one-week average difference (AD)" to detrend the data and it can avoid the aforementioned weaknesses reasons. Where the proposed method does not depend on time step, it working with the whole time period, so weakness (1) and (2) will be avoided. The third weakness happens during using polynomial equations in detrending TEC, so our proposed method can be more sensitive for the lower-frequency variations, especially, in the quiet geomagnetic conditions and the stable state of solar radiation over mid-latitude areas, where it depends on the average value. Accordingly, using different Detrended Fluctuations Analysis (DFA) techniques could increase the verification chances of the detectable span for perturbation duration.

The structure of the next part of this paper is as follows: section 2 describes datasets and methods for calculating the slant TEC (STEC), and the detrending methods, section 3 covers the results and discussion of STEC and detectable dTEC perturbations through three different detrending methods: Multi-step numerical difference, $6^{\text {th }}$ order polynomials fitting, and one-week average difference. Eventually, section 4 declares summarized Conclusions.

\section{Data and Methods}

\subsection{Dataset materials}

In Wuhan, precipitation is a characteristic of the city, about 6.2 months for a wetter season from February 22 to August 30, versus 5.8 for a drier season from August 30 to February 22 for more details we can refer to (https://weatherspark.com/y/128408/Average-Weather-in-Wuhan-China-Year-Round). Among the rainy days, we differentiate between those that experience rain alone or a mixture of rain and thunderstorms. The common form of precipitation throughout the year is rain alone. Wuhan residents received a warning message from Wuhan Meteorological Observatory at 16:26 (LT) where (LT $=$ UT +8 hours) on March 2 (DOY61), 2018. Wuhan Citizens were notified for being careful of 6 hours of sudden lightning activity with rainfall 20-40 mm over Wuhan city. The lightning was started at 17:00 am and continued to 23:00 pm according to local time. Besides, the strong thunderstorm over Wuhan City has been reported by the "time and date" website (Table 1 shows the weather and the strong thunderstorm hit Wuhan City started at 17:00 Local time (9:00 UTC)), where Wuhan Time = UTC +8 hrs), taking into consideration the light rain, rain and Fog at the same day happened without existing of thunderstorms and the lightning for more details we can refer to (https://www.timeanddate.com/weather/china/wuhan/ historic?month=3andyear=2018). The time period analyzed for this study is 8 nights from $22^{\text {nd }}$ February to $2^{\text {nd }}$ March (Doy54-Doy61) 2018, where our proposed method needs TEC values for one week before the event day to subtract from TEC of the event day in order to assess the ionospheric disturbance.

It is widely known that geomagnetic and solar activities can affect the ionosphere. Figure 1 displays the geomagnetic index Dst, Kp, and solar activity index F10.7 from Doy53 to Doy65 of 2018 around the Wuhan thunderstorms. The data of Dst, Kp are available from the National Aeronautics and Space Administration (NASA) with following: https://omniweb.gsfc.nasa.gov/form/dx1.html.

The GNSS dataset used in this study was provided by HBCORS with a sampling of $1 \mathrm{~s}$. This kind of sample rate has a high time-resolution. So, it may be more useful in detecting short-time irregular ionospheric disturbance. Meanwhile, the sampling rate of $1 \mathrm{~s}$ used occasionally may be based on data availability, long time in processing and/or large storage rates. HBCORS was constructed by a certain number of Continuously Operating Reference Stations (CORS). It uses satellite positioning technology, computer network technology, communication technology and many other technologies to provide accurate positioning in case of real-time, and space navigation positioning. Moreover, a service system for moving target-location information to help and support users and persons in charge. The average distance between each station is about $50 \sim 70 \mathrm{~km}$. Among them, about 21 reference stations are built on bedrock and the others' reference stations are built in the soil layer with relatively stable tectonic activity. The receivers include Trimble series R7 GNSS, NetR8, NetRS, in addition to Leica 1200. The observation uses a high precision geodetic antenna with a sampling interval of $30 \mathrm{~s} / 1 \mathrm{~s}$ for CORS stations. All the reference stations have an automatically operating system, in addition, the observation data are transmitted to the relevant data center through the network [(He et al., 2011; Nie et al., 2013; Zhang et al., 2013; Zhang et al., 2013]. This provides us a very good opportunity to detect ionospheric disturbances with high spatial and time resolution. 


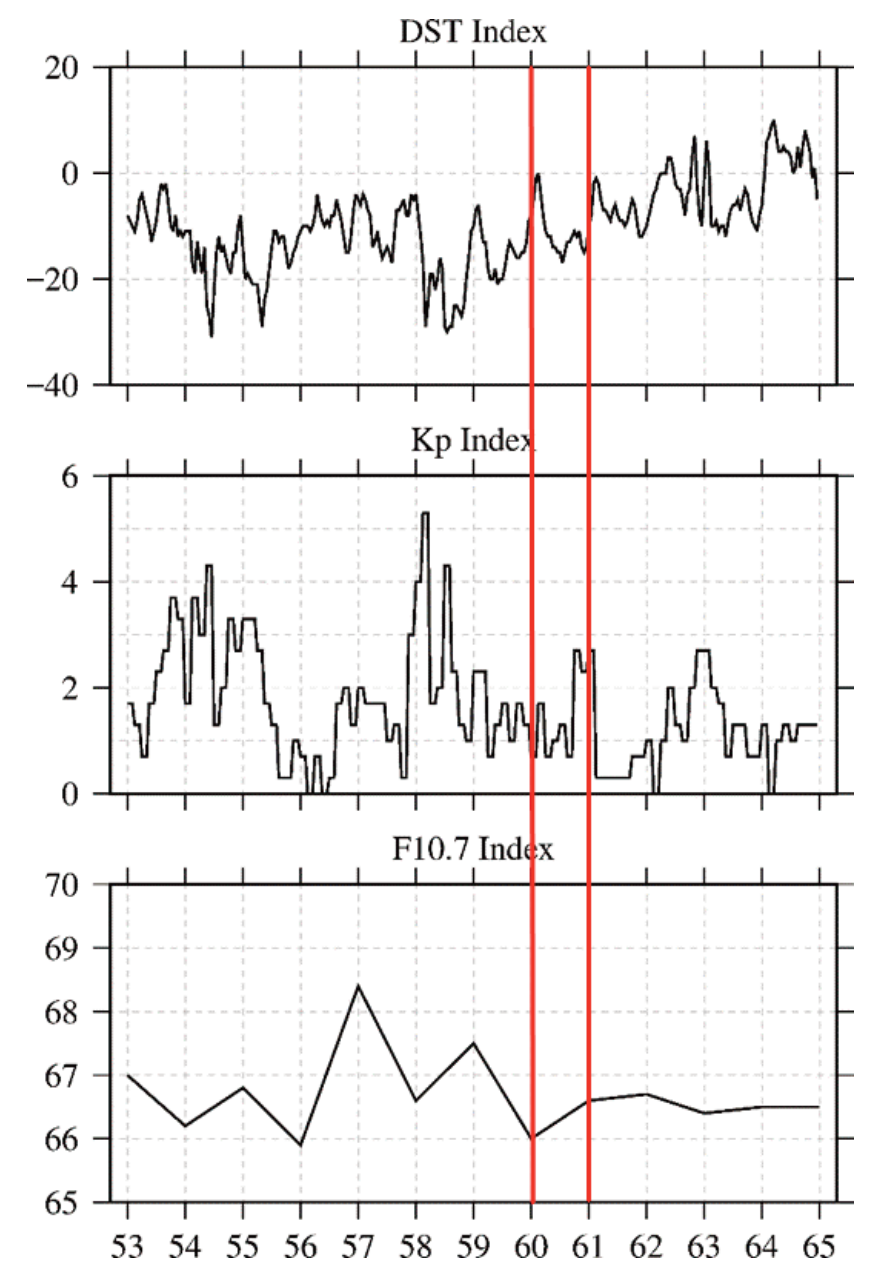

Figure 1. Dst, Kp, and F10.7 indices in the period from Doy53 to Doy65 of 2018. Horizontal axis represents Doys number while vertical axis shows the Dst, Kp, and F10.7 indices, respectively.

\subsection{STEC Calculation}

Ionospheric observables have been extensively discussed by Mannucci et al. [Ciraolo et al., 2007; Mannucci et al., 1998]. In fact, the ionosphere can cause an ionospheric delay on the GNSS signals, depending on their frequencies $f$ as well as STEC values extended along the line of sight (LoS) between the receiver and satellite. In this study, the STEC was derived from the dual-frequency GNSS observation from HBCORS as follows:

$$
\left\{\begin{array}{c}
P_{r, 4}^{S}=P_{r, 1}^{S}-P_{r, 2}^{S}=\frac{40.3 \times T E C}{f_{1}^{2}}-\frac{40.3 \times T E C}{f_{2}^{2}}+\left(B_{r, 1}-B_{r, 2}\right)+\left(B_{1}^{S}-B_{2}^{S}\right) \\
L_{r, 4}^{S}=L_{r, 1}^{S}-L_{r, 2}^{S}=\frac{40.3 \times T E C}{f_{1}^{2}}-\frac{40.3 \times T E C}{f_{2}^{2}}+\left(b_{r, 1}-b_{r, 2}\right)+\left(b_{1}^{S}-b_{2}^{S}\right)-\left(N_{r, 1}^{S}-N_{r, 2}^{S}\right)
\end{array}\right.
$$

Where $S$ and $r$ indicate satellite and receiver, respectively; TEC is the STEC along LoS; $L$ and $P$ are the carrier phase and pseudorange measurements, respectively; $f_{1}$ and $f_{2}$ are the frequencies of the carrier phases of $L_{1}$ and $L_{2}$, respectively; $B^{S}$ and $B_{r}$ are the satellite and receiver hardware delay of the pseudorange code, respectively; $b^{S}$ and $b_{r}$ are the satellite and receiver hardware delay of carrier phase, respectively; $N_{r, 1}^{S}$ and $N_{r, 1}^{S}$ are carrier-phase ambiguity.

Although the ionospheric observations can be derived directly from both pseudorange code or carrier phase measurement, the pseudorange measurement contains more noise than that of carrier phase. Therefore, the 
precision of the carrier phase is more accurate than that of the pseudorange. Moreover, it presents the additional problem of biased by unknown ambiguities [Mannucci et al., 1998]. Therefore, the so-called "leveling carrier to code" algorithms in this work are applied to minimize the noise of the pseudorange and to remove the ambiguity of the carrier phase [Ciraolo et al., 2007]. The differential carrier phase increases measurements precision of STEC while pseudorange gives the absolute scale of it [Ugur and Ibrahim, 2013]. This form can be represented as:

$$
\mathrm{L}_{\mathrm{I}, \mathrm{arc}}=\mathrm{L}_{\mathrm{I}, \mathrm{arc}}-\left(\mathrm{L}_{\mathrm{I}, \mathrm{arc}}-\mathrm{P}_{\mathrm{I}}\right)_{\operatorname{arc}}=\mathrm{TEC}+\mathrm{B}_{\mathrm{r}}+\mathrm{B}^{\mathrm{S}}+\left(\varepsilon_{\mathrm{p}}\right)_{\mathrm{arc}}+\varepsilon_{\mathrm{L}},
$$

Where $\mathrm{L}_{\mathrm{Larc}}$ is the ionospheric observable of carrier-phase "leveled" to the code-delay one, $\mathrm{L}_{\mathrm{I}, \mathrm{arc}}$ is the ionospheric observable obtained from carrier-phase; $\mathrm{B}_{\mathrm{r}}$ and $\mathrm{B}^{\mathrm{S}}$ are the same as Eq. (1), $\varepsilon_{\mathrm{p}}$ and $\varepsilon_{\mathrm{L}}$ are the noise and multi-path for the code-delay measurements and for the carrier-phase ionospheric observations, respectively.

Based on Eq. (2), taking leveling process into consideration: "(1) IFBs for carrier-phase are replaced by the corresponding code-delay IFBs" [Ciraolo et al., 2007]; (2) multi-path and noise presented in the code-delay measurements could affect the leveled carrier-phase ionospheric observable, in case these do not average to zero over the same continuous arc. In this study, we employed GPS data observed above $10^{\circ}$ cut off angle in order to have the longest arc as possible to check ionospheric disturbances with non-ionospheric related tracking errors. After processing all GNSS data, we can plot the STEC variation values versus time to detect the perturbations in the ionosphere without detrending. The previous method is conducted with an assumption that ionospheric perturbations have the same systematic error or STEC includes constant bias [X. Zhang and Tang, 2015].

The spatial distribution of TEC has been modeled by the spherical harmonic expansion based on single layer model as follow:

$$
\operatorname{VTEC}(\alpha, \lambda)=\sum_{n=0}^{n_{\max }} \sum_{m=0}^{n} \tilde{P}_{n m}(\sin \alpha)\left(\tilde{C}_{n m} \cos (m \lambda)+\tilde{S}_{n m} \sin (m \lambda)\right),
$$

Where $\alpha$ and $\lambda$ are the geomagnetic latitude and solar-fixed longitude for Ionospheric Pierce Points (IPP), respectively; $\operatorname{VTEC}(\alpha, \lambda)$ is the vertical ionospheric TEC at IPP. VTEC is converted from STEC using a mapping function (MF) [Deng et al., 2016; Schaer, 1999]. $n_{\max }$ is the max degree of the spherical function; $\tilde{P}_{n m}$ represents the fully normalized Legendre function of degree $\mathrm{n}$ and order $\mathrm{m} ; \tilde{C}_{n m}$ and $\tilde{S}_{n m}$ are the fully normalized spherical coefficients of degree $\mathrm{n}$ and order $\mathrm{m}$ [Zhang and Zhao, 2019].

Before estimating STEC from GPS observations, the TurboEdit algorithm was used to detect cycle slips. The established algorithm by Blewitt, can identify cycle slips, correct cycle slips wherever possible, even more, delete data outliers [Blewitt, 1990]. Based on the limited number of receivers and the study area, the expansion of spherical harmonics with order 3 is applied. The shell (single layer) has an altitude of about $450 \mathrm{~km}$. In this method, we have computed the differential code biases (DCBs) as a constant value per day as well as zero-average conditions are adopted for all observed satellites of each system in order to disconnect the DCBs of satellites and receivers from each other. Therefore, the cleaned STEC are extracted after separating the DCBs which can be applied for measuring and analyzing the ionospheric disturbances through this work. After obtaining the corrected STEC, we can get a STEC time series as follows: $\mathrm{STEC}_{1}, \mathrm{STEC}_{2}, \cdots, \mathrm{STEC}_{n}$. Where the subscripts $1,2, \ldots, \mathrm{n}$ introduce the epoch number started from one at midnight based on UT and end at 86400, where the total number of epochs represents for a whole day by seconds.

\subsection{Detrending methods}

\subsubsection{Multi-step numerical difference}

For a given STEC sequence, Hernandez-Pajares et al., [2006] have extracted ionospheric disturbances by applying a numerical difference method with an order of 1 . Recently, other researchers have applied the multi-step multi-order with higher orders 2 and 3 [Park et al., 2011; Zhang and Tang, 2015]. The multi-order numerical difference is defined: 


$$
\Delta \mathrm{k}(\mathrm{t})=\Delta \mathrm{k}(\mathrm{t})-(\Delta \mathrm{k}(\mathrm{t}+\tau)+\Delta \mathrm{k}(\mathrm{t}-\tau)) / 2
$$

Where $t$ is the sampling rate of the data, $\tau$ is the time step, which was chosen to detect the possible variations $(\Delta \mathrm{k})$ in TEC with a specific time difference. Apparently, the ionospheric disturbances may skip detectable disturbance because the time step could be relevant to the detectable period. Hereinafter, to solve this problem, we chose multiple time periods $(30,90,300) \mathrm{s}$. Obviously, these different time steps increase the chances of verification the detectable span for perturbation duration. In such kind of detrending, as shown in the next equation we have two different amplitudes $\mathrm{A}$ and $\mathrm{A}$ ' for $\Delta \mathrm{Lj}$ and ionospheric disturbances, respectively, which rest on (T), is the ionospheric disturbances period [Hernandez-Pajares et al., 2006].

$$
\mathrm{A}^{\prime}=2 \mathrm{~A} \cdot \sin 2 \frac{\tau \cdot \pi}{\mathrm{T}}
$$

Assuming TEC trendlines have linear changes during a short period. In other words, the applied method will detect ionospheric disturbance periods of $600 \mathrm{~S}\left(\mathrm{~A}^{\prime}=2 \mathrm{~A}\right)$ with significant sensitivity, and periods between $(400-1200) \mathrm{S}$ where $\left(A^{\prime}=A\right)$, will be quite efficient [Hernandez-Pajares et al., 2006; Zhang and Tang, 2015]. Mostly, this type of problems happens in all detrending procedures commonly, so in this study, we investigate the suitability of a deterministic technique to display the strong thunderstorm fluctuations by employing two more of detrending methods; they are described in sections 2.3 .2 and 2.3.3, respectively.

\subsubsection{Six order polynomials fitting}

In this strategy, the TEC data are fitted with a $6^{\text {th }}$ order polynomial as a second method to detrend the data, in order to sensitively observe TEC fluctuations.

$$
P(x)=\sum_{i=0}^{n-1} a_{i} x^{i}
$$

$6^{\text {th }}$ order being the highest that can be displayed with the trend line. The disturbed TEC is computed by subtracting this fitting from the STEC data. We got that ionospheric perturbations as a function in TEC variations are closely correlated in space and time during the strong underlying electrical storm. The aforementioned process removes the gross offset, as well as the detrended values, are mostly related to the carrier phase TEC around 0.01 to 0.1 TECU accuracy [Burrell et al., 2009].

\subsubsection{One-week average difference}

The following is the proposed method employed to detect ionospheric disturbances based on the average of one week before the phenomena day. Subtraction of the average simultaneous observations from a certain day can lead to an observable residual, in other words, removing an aspect from the dataset arise some kind of distortion or disturbance can appear in the behavior of the output. As mentioned above, the mathematical process for this kind of detrending can be described in the next simple equations.

$$
\begin{gathered}
\hat{K}=\left(\mathrm{K}_{\text {Doy } 54}+\mathrm{K}_{\text {Doy } 55}+\ldots .+\mathrm{K}_{\text {Doy } 60}\right) / 7, \\
\mathrm{~V}=\mathrm{K}_{\text {Doyi }}-\hat{\mathrm{K}}
\end{gathered}
$$

Where $\mathrm{K}$ is the average value of STEC for period one week before electrical storm, V is the residuals between a certain day and average value. In the assumption, TEC trendlines have linear changes during a short period. Furthermore, the Dst index, geomagnetic Kp index, and the solar radio flux F10.7 index during the study period were quite steady, based on Figure 1. So, the values of TEC for the average simultaneous observations supposed to be almost close to each other. The difference between TEC value for average and a certain day should be smooth 
or/and have a constant shift. The average value calculated from Doy54 to Doy60, afterward, the mean values subtracted from Doy60 (Day before phenomena) and Doy61 (Day of phenomena), respectively. The next section represents the results and their discussion

\section{Results and Discussion}

\subsection{Geomagnetic index Dst, Kp, and solar activity index F10.7}

The Disturbance storm-time (Dst) index, geomagnetic Kp index, and the solar radio flux F10.7 index during 12 Days (Doy53-Doy65) are depicted below in Figure 1. The periods between the red lines indicate the time when a strong thunderstorm hit Wuhan. The Kp index value is an indication of mid-high latitude geomagnetic activities. In general, values less than 4 can indicate that there is a steady-state of geomagnetic activity. As we can see, during the whole period, no presence of strong geomagnetic activity or solar activity is observed. Low geomagnetic activity $(\mathrm{Kp}<4)$, except Doy54 Kp $\leq 4.3$ and Doy58 has the highest $\mathrm{Kp} ~ 5.3$, indicating a moderate geomagnetic activity. Except for Doy54, 58, the geomagnetic conditions are quiet with Dst $<-35 \mathrm{nT}$, and $\mathrm{Kp} \leq 4$. The solar radiation is in a stable state, according to the F10.7 index variation, within 0.3 and $2.5 \%$ of its average value (from Doy53 to Doy65). The Dst index was quite steady and varied from $-31 \mathrm{nT}$ to $10 \mathrm{nT}$ as min and max value, respectively. Overall condition of geomagnetic index Dst, Kp, and solar activity index F10.7 are in steady-state during the day of phenomenon (Doy 61).

\subsection{Disturbances by STEC observations}

According to Wuhan Meteorological Observatory, the lightning warning classified as yellow signal besides their strong thunderstorm occurred at 09:00 UT (05:00 pm LT) on $2^{\text {nd }}$ March 2018 as shown in Table 1 for more details we can refer to (https://www.timeanddate.com/weather/china/wuhan/historic?month=3andyear=2018). Based on code-delay and Dual-frequency carrier phase GPS observations are combined to obtain ionospheric observables represented as the STEC along the LoS between satellite and receiver. Both the transmitting and the receiving hardware cause differential code biases (DCB) could have an effect on observations [Ciraolo et al., 2007]. These biases have been estimated and eliminated from the data to adjust the experimental STEC. However, assuming STEC still contains bias, it is supposed to have a constant bias [Zhang and Tang, 2015]. According to this assumption, we analyzed the STEC to detect the ionospheric disturbances then verified the results with VTEC. Finally, the ionospheric disturbances are assessed with three detrending methods.

\begin{tabular}{ccc} 
& \multicolumn{2}{c}{ Conditions } \\
Time & Temp & Weather \\
12:00 PM & $50^{\circ} \mathrm{F}$ & Fog. \\
\hline 2:00 PM & $55^{\circ} \mathrm{F}$ & Haze. \\
\hline 3:00 PM & $55^{\circ} \mathrm{F}$ & Haze. \\
\hline 4:00 PM & $55^{\circ} \mathrm{F}$ & Scattered clouds. \\
\hline $5: 00 \mathrm{PM}$ & $52^{\circ} \mathrm{F}$ & Strong thunderstorms. Fog. \\
\hline $6: 00 \mathrm{PM}$ & $52^{\circ} \mathrm{F}$ & Thunderstorms. Fog. \\
\hline $7: 00 \mathrm{PM}$ & $52^{\circ} \mathrm{F}$ & Light rain. Fog. \\
\hline 8:00 PM & $52^{\circ} \mathrm{F}$ & Light rain. Fog. \\
\hline 9:00 PM & $52^{\circ} \mathrm{F}$ & Light rain. Fog. \\
\hline
\end{tabular}

Table 1. The weather conditions over Wuhan on March 2nd, 2018 from 12:00 pm to 9:00 pm (Local Time). (www.timeanddate.com) 


\section{Mohamed Freeshah et al.}

Figure 2 displays the ionospheric STEC (which contains constant bias) derived from the dual-frequency GPS data of PRN 28 over station WH04. Since the ionospheric presence depends on solar radiation, a big part of ionospheric change due to the earth relative position with respect to the sun. In addition, zenith angle and earth rotation/24 h, widely contribute to the daily ionospheric variations [Amieri-Simkooei and Asgari, 2012]. We selected the satellite which has observations at nighttime, where it covered the time before and during the lightning. Generally, the behavior of the ionosphere is in steady-state during the night. Some ionospheric layers going to disappear, so STEC supposed to decrease or at least become a fixed value in normal conditions [Zolesi and Cander, 2014]. Consequently, the ionospheric disturbances in these times may be caused by lightning and their thunderstorms effects, especially this phenomenon happened after the sunset with respect to China local time (UT+8h). The red arrows in Figure 2 show the disturbed TEC during 14:20-15:03UT separately, to distinguish the ionospheric disturbances arrival time. The two arrows mark the larger instabilities in STEC. The arrow "A" marks the first arrival disturbances in STEC, indicates the first longest disturbed period of approximately 15 to $20 \mathrm{~min}$ by the "black double arrow". The arrow "B" shows the extreme deviation started with positive disturbance. Afterward, STEC has decreased and deviated from fitted value through the aforesaid duration, within 3-6 min.

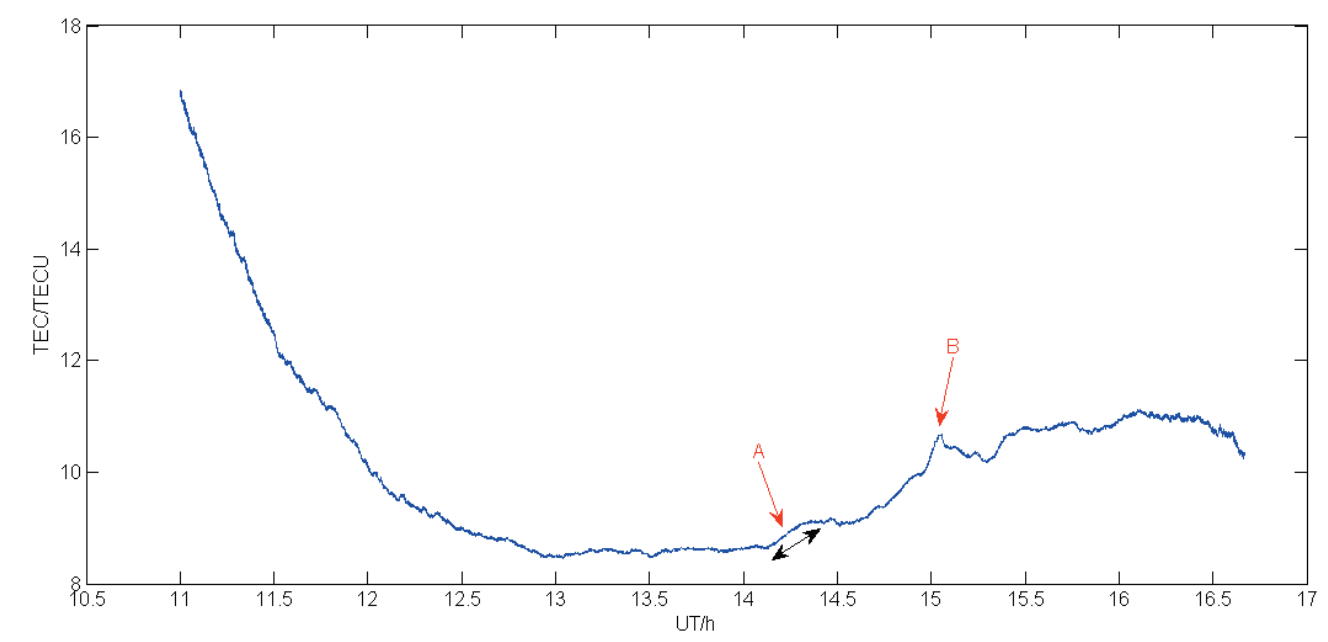

Figure 2. The Ionospheric STEC obtained by GPS observations of the satellite PRN 28 at station WH04. The two arrows indicate the arrival time of ionospheric disturbances.

Furthermore, Ionospheric STEC obtained by GPS observations of satellite PRN 28 over WH04 (Figure 2) coincide with another 5 CORS stations named as XF01, XF05, XG01, XG04 and XN01, shown in Figure 3. Meanwhile, all the 6 CORS stations have STEC perturbations synchronize with the lightning duration. As we can see, the disturbances appearance differs within a few mins over various stations depending on some elements such as the location of each station, IPP position as well as Shell altitude.

According to Figure 3, the red arrows indicate the extreme ionospheric disturbances found after a few hours of the start-time of thunderstorms. This may depend on the electrical energy that have been generated by the lightning (lightning is generated in electrically charged storm systems) [NASA Facts, 2006] which affect vertically in troposphere layer, takes some time to trigger ionosphere taking into account thunderstorms have lasted for several hours. In addition, lightning phenomenon consists of multi-epicenters with different locations with various influence for only the surrounding areas close to it. Based on the previous reasons, in addition, the STEC have been calculated by GPS along LoS and only for distinct IPP. Logically, this factor may associate with the delayed time for the detectable ionospheric disturbances as well as it can cause some undetectable ionospheric disturbances. On the other hand, the corresponding routes of the IPP created from LoS intersect the shell (single layer) with 450km altitude, which represents a distinct longitude and latitude with a specific time for each IPP point as well as these satellites have different elevation angles. Logically, some IPP can be located in the disturbed area, therefore, use in sensing the ionospheric disturbance within the time of ionospheric fluctuations. 
TEC Disturbances by CORS at Thunderstorm
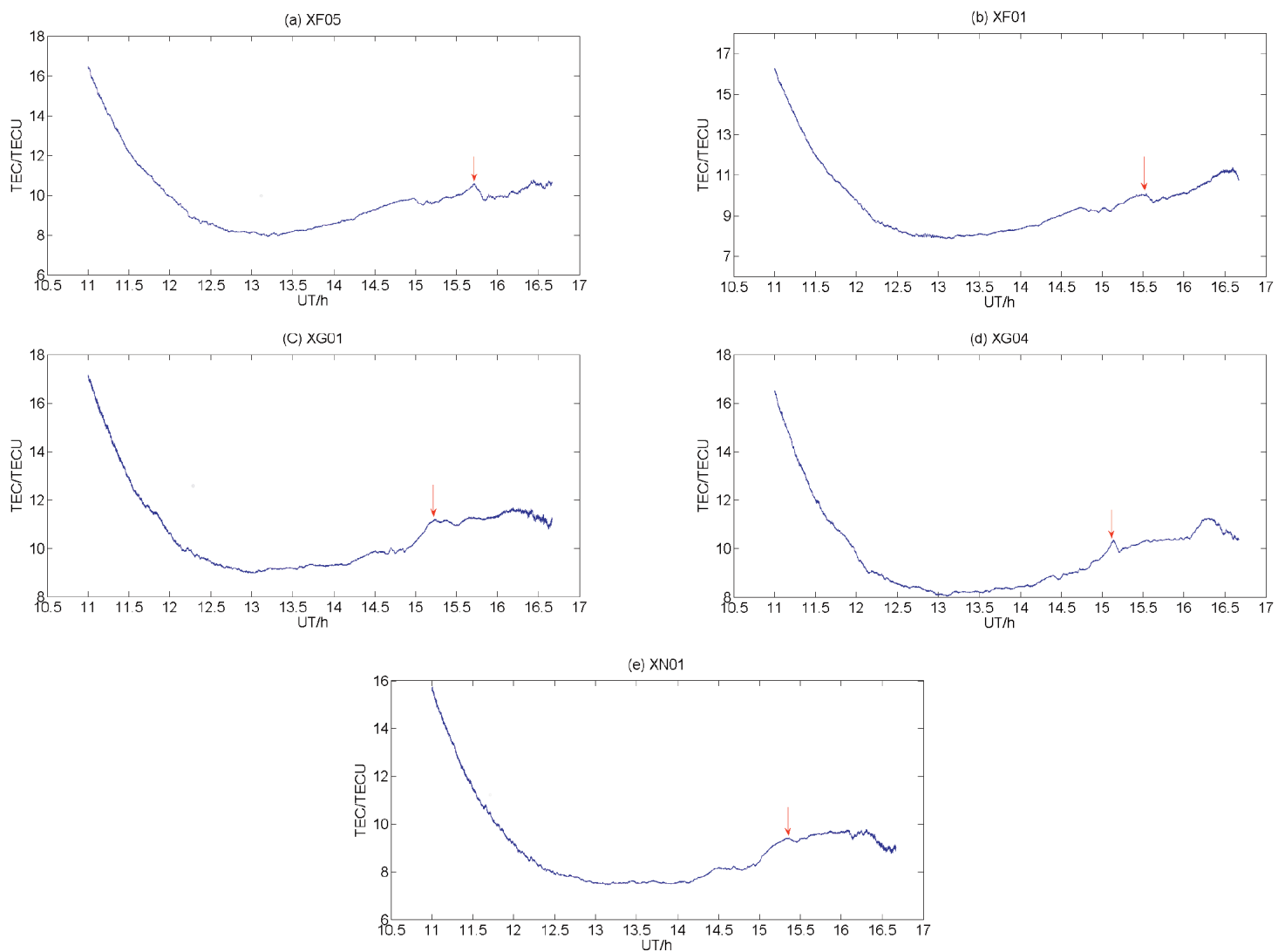

Figure 3. The Ionospheric STEC obtained by GPS observations of satellite PRN 28 at stations XF01, XF05, XG01, XG04 and XN01, Panels (a-e) present disturbance series.

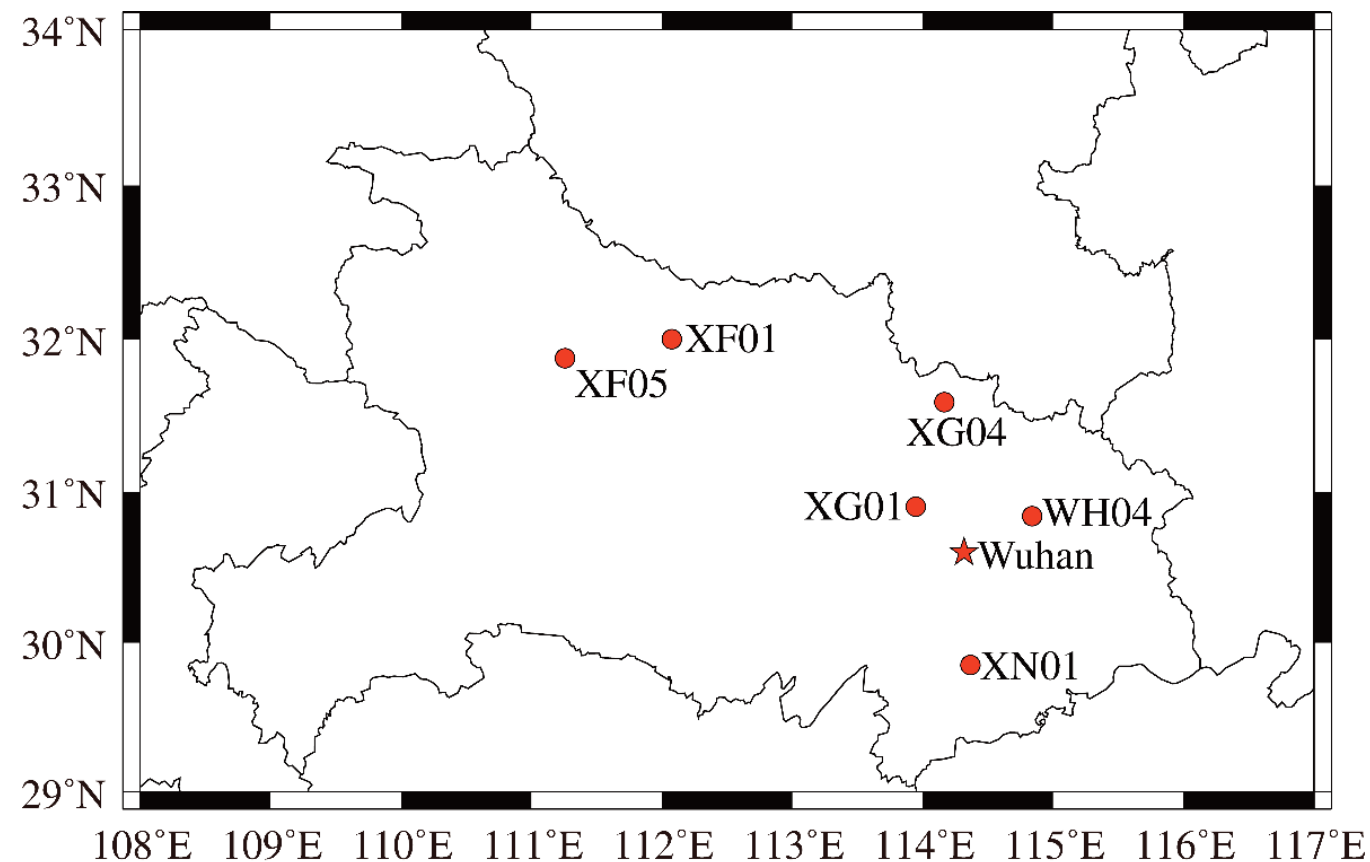

Figure 4. Shows the location of Wuhan city center (the red star) and the 6 CORS stations (red circles). 


\section{Mohamed Freeshah et al.}

The ionospheric STEC series also contains a significant disturbances during 15:00-15:45UT, as shown in Figure 3 the perturbations can be considered as extreme values of ionospheric disturbances which happened up to $45 \mathrm{~min}$ separately over most of the ground-based stations. Based on Figure 2, 3 we can see that ionospheric disturbances over WH04 moved quicker than other points. Where the "B" arrow refers to an earlier time of ionospheric disturbances than the red arrows for all panels in Figure 3. By referring to Figure 4, we can interpret ionospheric disturbances moved quickly in N-E direction over WH04 located $58 \mathrm{~km}$ close to the city center of Wuhan. Where the turbulence reached the highest value at 15:03UT. However, the XG01 10km closer than WH04 to the city center, but the highest perturbations have delayed about 11 min at 15:14UT. For the N-W direction, the detectable large ionospheric disturbances were nearly 40min overdue than WH04, where the furthest station named as XF05 located about $323 \mathrm{~km}$ in the same direction from Wuhan city center. In accordance with the above results, the detected ionospheric disturbances have different horizontal velocity, period, direction, waveform and observed time compared with the reflected lightning and their thunderstorms time period. Furthermore, a possible recurrent ionospheric disturbance has been checked, we also verified that there were not significant perturbations for one week before the day of the phenomenon at the same study times.

Based on the main concept of TEC during the night, it should be discharged and decrease because of nonexistance of solar radiation to recharge it. However, solar radiation is the major element which associates in recharge ionospheric particles. As it is known, through the nighttime there are some ionospheric layers such as D and E which disappear [Zolesi and Cander, 2014]. Therefore, in the steady states, the TEC values decrease. However, TEC values have increased during nighttime which is likely to support our interpretation that electrical energy generated by lightning could contribute in ionospheric fluctuations by vertical coupling between troposphere activities and higher atmosphere. As a result, the TEC has been disturbed. These results can confirm that the observed ionospheric disturbances in Figure 3 is triggered by the electrical energy that have been generated by lightning waves for the next reasons (1) The detected ionospheric disturbances happened during the nighttime where no solar radiation which is the main factor to recharge ions in the ionosphere. (2) As we can see in Figure 1, during the whole day of the event (DOY 61), no presence of strong geomagnetic activity or solar activity is observed so no effect came from DST, Kp, and F10.7. In the next section, we used detrended methods to remove the effects of accumulated errors to display individually the ionospheric changes in TEC values.

\subsection{Results of Detrended methods}

In order to assess the ionospheric disturbances explained in section 3.2. It is worth considering the removal of the effects of accumulated errors to display individually the ionospheric changes in TEC values. Therefore, multiple detrending techniques are applied in the next sections which show their results, discussion, and analysis listed below.

\subsubsection{Multi-step numerical difference}

Based on the results shown in Figure 5, two types of ionospheric disturbances were detected by the GPS station XG04 after the Wuhan strong thunderstorms. Ionospheric disturbances in panel (c) are a high-frequency wave with periods of approximately (time) 1 to $2 \mathrm{~min}$, whereas ionospheric disturbances shown in (a) and (b) are low-frequency waves with periods of approximately 2 to $5 \mathrm{~min}$. As a result, in thunderstorm could produce ionospheric disturbances with different frequencies and time period. In addition, $300 \mathrm{~s}$ is better than the other time steps (30 and 90) $\mathrm{s}$ in order to detect the high ionospheric disturbances. Three other stations WH04, XF01 and XF05 also observed high ionospheric disturbances by employing $300 \mathrm{~s}$ as a time step Figure 6. Nevertheless, the (30 and 90) s are not good enough over the same stations.

It is interesting to note that using time step $300 \mathrm{~s}$ is more sufficient to detect the ionospheric disturbance which is an indication of ionospheric response to a strong thunderstorm [Zhang and Tang, 2015]. As we can see in Figure 5, 6 the detectable ionospheric disturbances for the four stations XG04, WH04, XF01, and XF05 are coincident with the time of lightning over Wuhan city. The few minutes difference between disturbance for the aforementioned stations may be due to their different locations. The detectable ionospheric disturbances time range is started around 15:00 UT and has ended about 15:40 UT. 

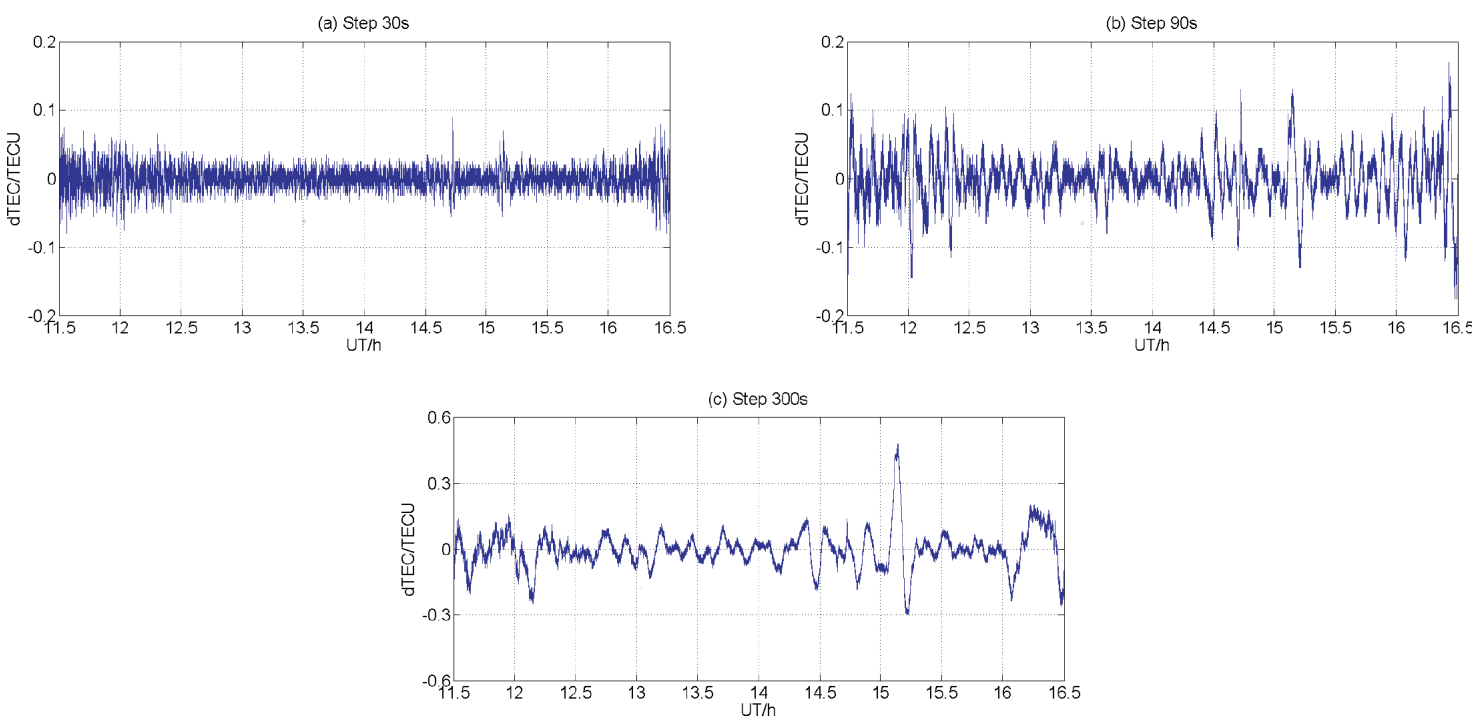

Figure 5. Detecting ionospheric disturbances series by Multi-step numerical difference technique at station XG04, the order is set to 1 , using three different time steps (30, 90 and 300) s, respectively. Panels (a-c) show the results.
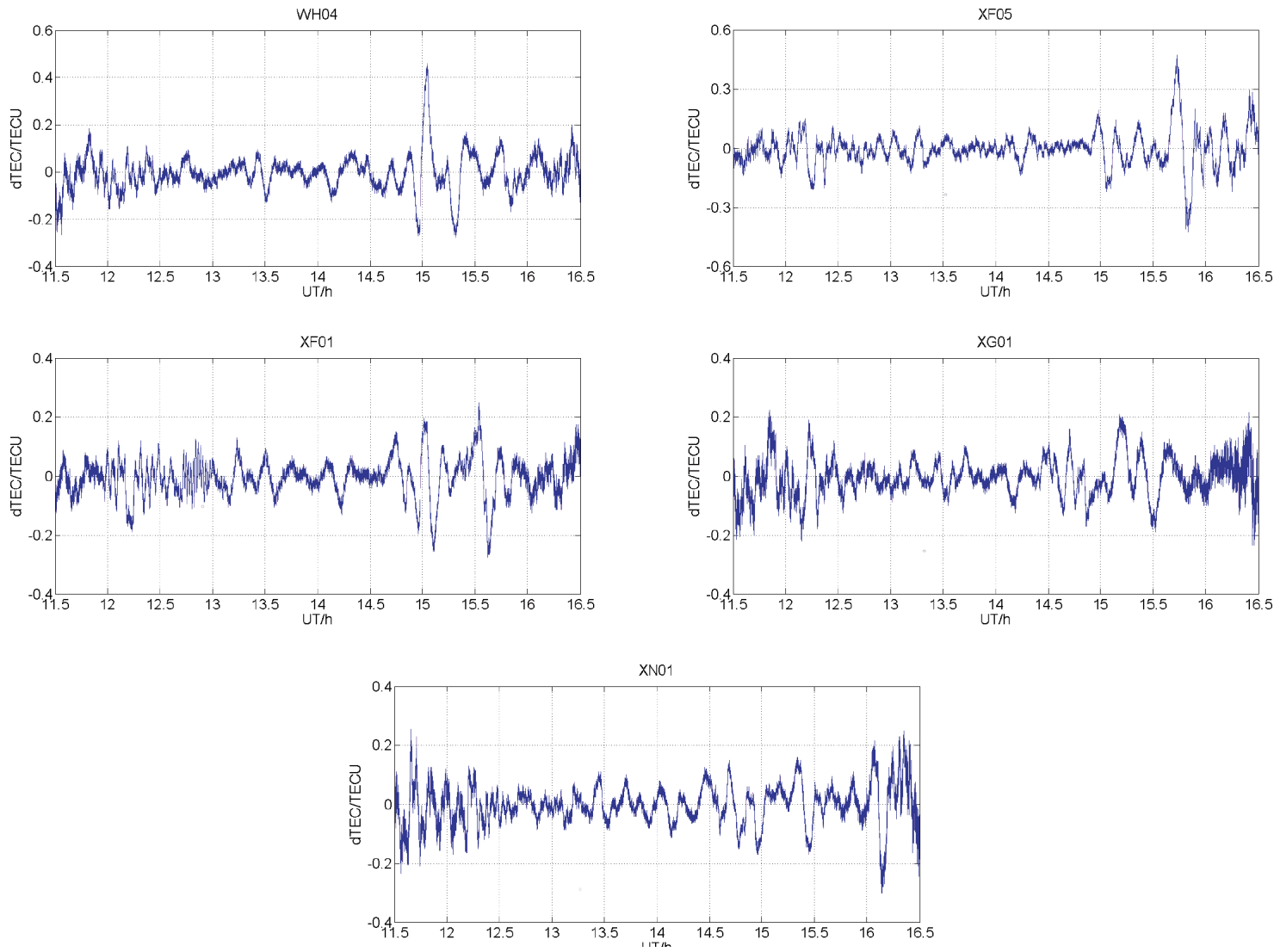

Figure 6. Detecting ionospheric disturbances series by Multi-step numerical difference technique over other five stations, the order is set to 1 , using $300 \mathrm{~S}$ time step $300 \mathrm{~s}$. 


\section{Mohamed Freeshah et al.}

It is acknowledged that the chosen time step could be relevant to the detectable period, so a certain time step may skip detectable perturbations. Using the same criteria, there are no detectable perturbations over the other two stations XG01 and XN01, although there are detectable ionospheric disturbances over the same stations in Figure 3. As a result, we need to apply other techniques, where the pre-analysis mentioned based on Figure 3 indicates the aforementioned stations have disturbance common with the time period of lightning over Wuhan. Consequently, Multi-step numerical difference is not enough to assess the detectable ionospheric turbulences response to the studied phenomena overall disturbed stations.

\subsubsection{Six order polynomials fitting}

Hereinafter, the results of detrending by polynomial fitting for TEC have displayed through the same 6 CORS stations. The disturbed TEC is computed by subtracting this fitting from the STEC data.

The satellite has the given GPS pseudo-random number (PRN) 28. In Figure 7, the measured STEC has large deviations from the fitted curve between 14:30 and 16:00 UTC. The vertical green lines show the period of the STEC deviations from the fitted curve. This time range indicates that may detectable ionospheric disturbances can be found based on the large deviations. In addition, the corresponding time ionospheric disturbances which detected by the first method "Multi-step numerical difference". The applied method is more reliable for higherfrequency variations, in other words, it acts to filter out the lower-frequency changes [Lay et al., 2013].

By deducting the observed TEC from the best fit $6^{\text {th }}$ order polynomial, the deviation can be detected easily. The performance of this kind of detrending for the six disturbed stations has more efficiency than the method of "Multi-step numerical difference" which mentioned separately in section 3.3.1. The ionospheric disturbances over the stations XG01, XG04, WH04, XF05, and XG04 are successfully detected by the current method as shown in Figure 8. However, the first two stations (XG01, XG04) are non-detectable by "Multi-step numerical difference" method, and the last three stations (WH04, XF05, and XG04) are detected by both techniques. Although the current technique using best fitting polynomials apparently has a better performance than the first one. "Multistep numerical difference" has found a detectable ionospheric disturbance over the station XF01, which was not observed by subtracting the fitted-curve method from the data. Polynomial fitting acts to filter out the lowerfrequency changes so it cannot detect the lower values disturbances. For this reason, we proposed a third detrending method to avoid these defects.

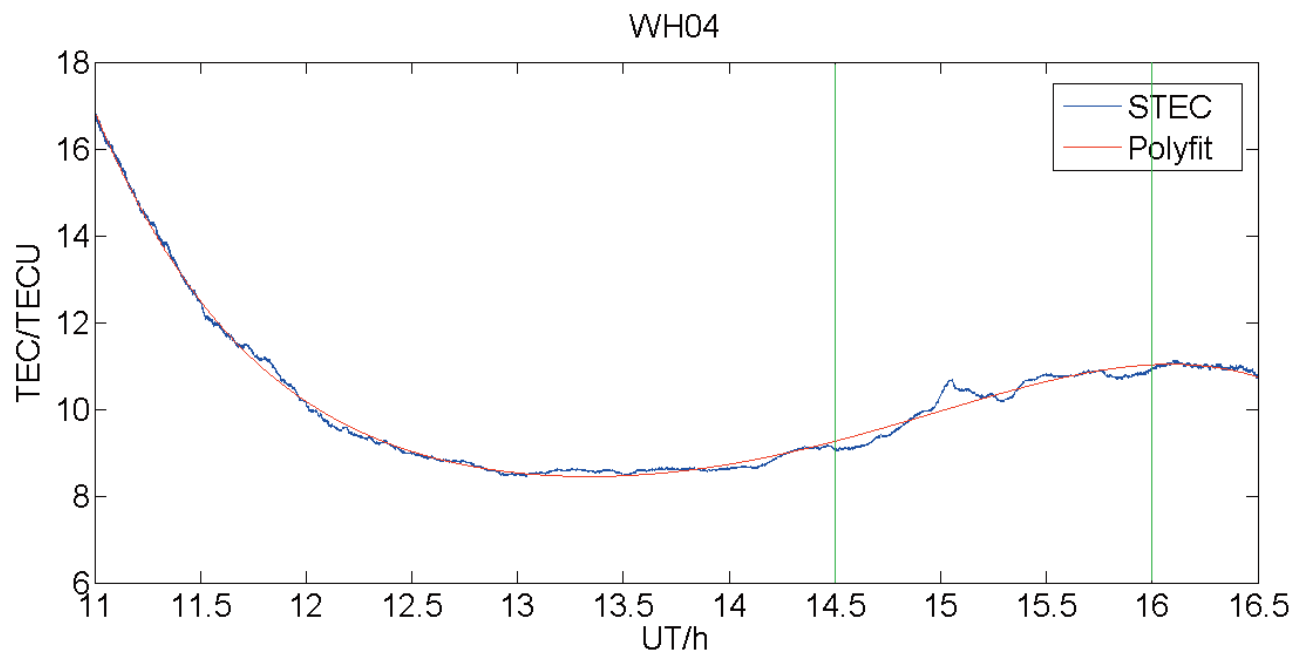

Figure 7. The deviations between the measured TEC and the $6^{\text {th }}$ order polynomial fitted curve for the given GPS pseudo-random number (PRN) 28 over station WH04. 

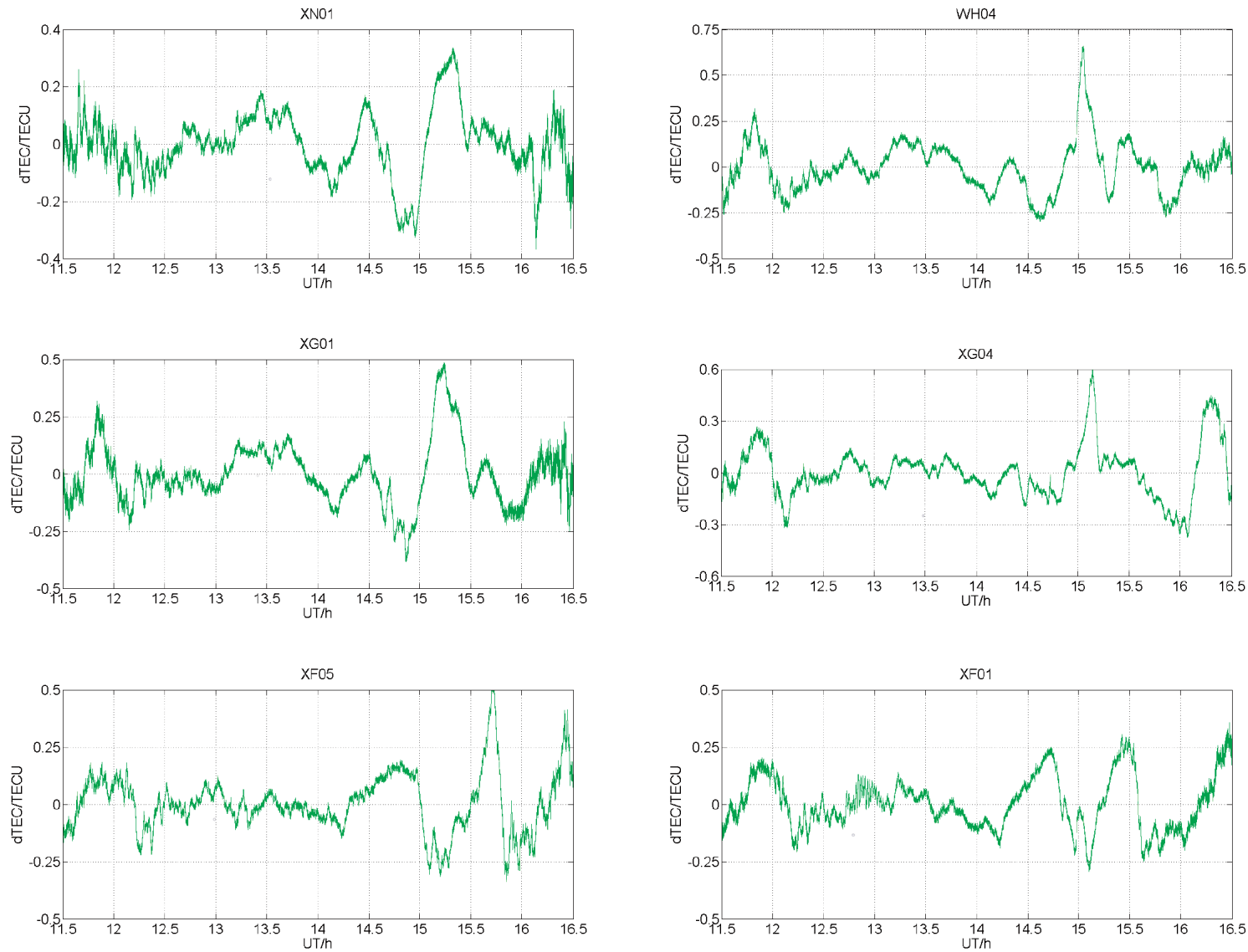

Figure 8. Differences between the measured TEC and the 6th order polynomial fitted curve for the given GPS pseudo-random number (PRN) 28 over 6 ground-based stations.

\subsubsection{One-week average difference}

In the assumption, TEC trendlines have linear changes during a short period. Furthermore, the Dst index, geomagnetic Kp index, and the solar radio flux F10.7 index during the study period were quite steady, based on Figure 1. So, the values of TEC for the average simultaneous observations supposed to be almost close to each other. The average value calculated from Doy54 to Doy60, afterward, the mean values subtracted from Doy60 (Day before phenomena) and Doy61 (Day of phenomena), respectively. The results of these experiment shown in Figure 9 below.

The anomalous TEC changes are found closely associated in space and time to the strong underlying lightning and their thunderstorms. The TEC variations are observed with maxima and minima to be $\sim 2.5$ and 0.5 TECU, respectively, through typical hours of darkness background value of numerous TECUs. The changes close to the thunderstorm appear to have a quick response than those away from the storm. In addition, there was a highfrequency content over the nearest neighbors' stations, especially in the N-E direction from Wuhan city center with periods of minutes to tens of minutes. The ionospheric disturbances lasted for a longer time than South direction by a few minutes, based on the results over XG04 and XN01 in the North and South of Wuhan city center, respectively. The TEC perturbations have ended in the N-W direction over XF05 station later than other stations around the Area of interest (AOI). These findings are warranted by the pre-analysis over the same station which located about $323 \mathrm{~km}$ (all distances measured from Wuhan city center).

Indeed, the turbulences are coming later comparing to other stations, taking into consideration the direction and the farther distance away from Wuhan city center. With ingesting deep, the N-W direction seems to have the last detectable large ionospheric disturbances, was nearly 40min overdue than WH04. The detectable localized TEC variations for XF05 is observed at night of the strong thunderstorm. It was found that the TEC perturbations finished with minutes to tens of minutes after other stations. Emphatically, both results of the large and last ionospheric 


\section{Mohamed Freeshah et al.}

disturbances which can be detectable coincide with the ionospheric disturbances moved quickly in N-E direction on the other side, shifted little faster in the N-W direction. As a result, Multiple epicenters of the lightning and their thunderstorm might be concentrated near to the center of the city and to N-E direction during that night. Moreover, ionospheric disturbances can travel with different velocities in the case of thunderstorms depending on the direction as well as the remoteness from the electrical storm.

By comparing the results of the second and third detrending technique, where both techniques agree in more than $80 \%$ of the detectable ionospheric disturbances. Around 5 CORS stations have detected ionospheric disturbances except for XF01 station discovered only by the third method. Based on the results for both methods, the $6^{\text {th }}$ order polynomial technique delayed within mins to tens of mins from the mean method for detecting ionospheric disturbances. The only non-detectable ionospheric disturbance for station XF01 by the fitting technique which has variations less than 1TECU during the common time with phenomena effect. Emphatically, this finding agrees with the concept of fitting is acted more sensitive only for the higher-frequency variations [Lay et al., 2013].

It is worthy of mentioning that under large ionospheric electron disturbances based on lightning and their thunderstorms, significant ionospheric disturbances maybe in some detrending styles. On the basis of this study results, and according to Table 2 the third method called "one-week average difference" has the best performance agree with our pre-analysis. Where the third method has detected the ionospheric disturbances over the 6 CORS stations. This type of detrending technique is more significant especially in mid-latitude locations with quite steady solar radio flux F10.7 and moderate geomagnetic storm Kp based on research findings.

\begin{tabular}{cccc} 
CORS Station Name & Method 1 & Method 2 & Method 3 \\
& MSND & PF & AD \\
\hline WH04 & Detected & Detected & Detected \\
\hline XF01 & Detected & undetected & Detected \\
\hline XF05 & Detected & Detected & Detected \\
\hline XG01 & undetected & Detected & Detected \\
\hline XG04 & Detected & Detected & Detected \\
\hline XN01 & undetected & Detected & Detected \\
\hline
\end{tabular}

Table 2. Shows the final status of detected and undetected ionospheric disturbances over 6 CORS stations by three detrending techniques.

It is known that the tropospheric activities like thunderstorms could disturb the lower ionosphere of height range 60 to $90 \mathrm{~km}$ through lightning-generated electric fields [(Cheng et al., 2007; Davis and Lo, 2008; Lu, 2006; Pasko et al., 1997; Mende et al., 2005] as well as the convective atmospheric gravity waves (GWs) [Lay and Shao, 2011; Sentman et al., 2003; Taylor and Hapgood, 1988]. Besides, [Davis and Johnson, 2005; Yu et al., 2015] have found that the ionospheric sporadic $\mathrm{E}$ of altitude $\sim 100 \mathrm{~km}$ could be affected by lightning. Recently, researchers have reported that the roles of ionization enhancements could happen through the lightning, and thunderstorms can trigger atmospheric gravity waves (AGWs) and propagate upwards to the ionosphere [Yue and Lyons, 2015]. It is known that GWs are considered as a crucial part of the atmosphere's dynamics process. GWs influence temperature and atmospheric winds distribution where it mainly contributes to moving momentum and energy between the different layers of the atmosphere. Once GWs arrive at the upper atmosphere and interact with the plasma of ionosphere, the density of plasma is disturbed, electron density is also changed according to the law of conservation of charge, and causes the ionospheric disturbances. In 2017, Yu et al. have tried to find the relation between Earth's atmosphere and ionosphere interactions, their results indicated that electric field effects and GWs likely the mechanisms responsible enhancement of Na layer [Yu et al., 2017]. Subsequently, Yu, B. et al. have concluded that the dynamical process of the ionosphere's sporadic $\mathrm{E}$ layers and Na layer dominantly effect by atmospheric tides. Their findings indicated that metallic layered has been intensified by atmospheric tides or in other words the troposphere-mesosphere-ionosphere coupling [Yu et al., 2019]. 

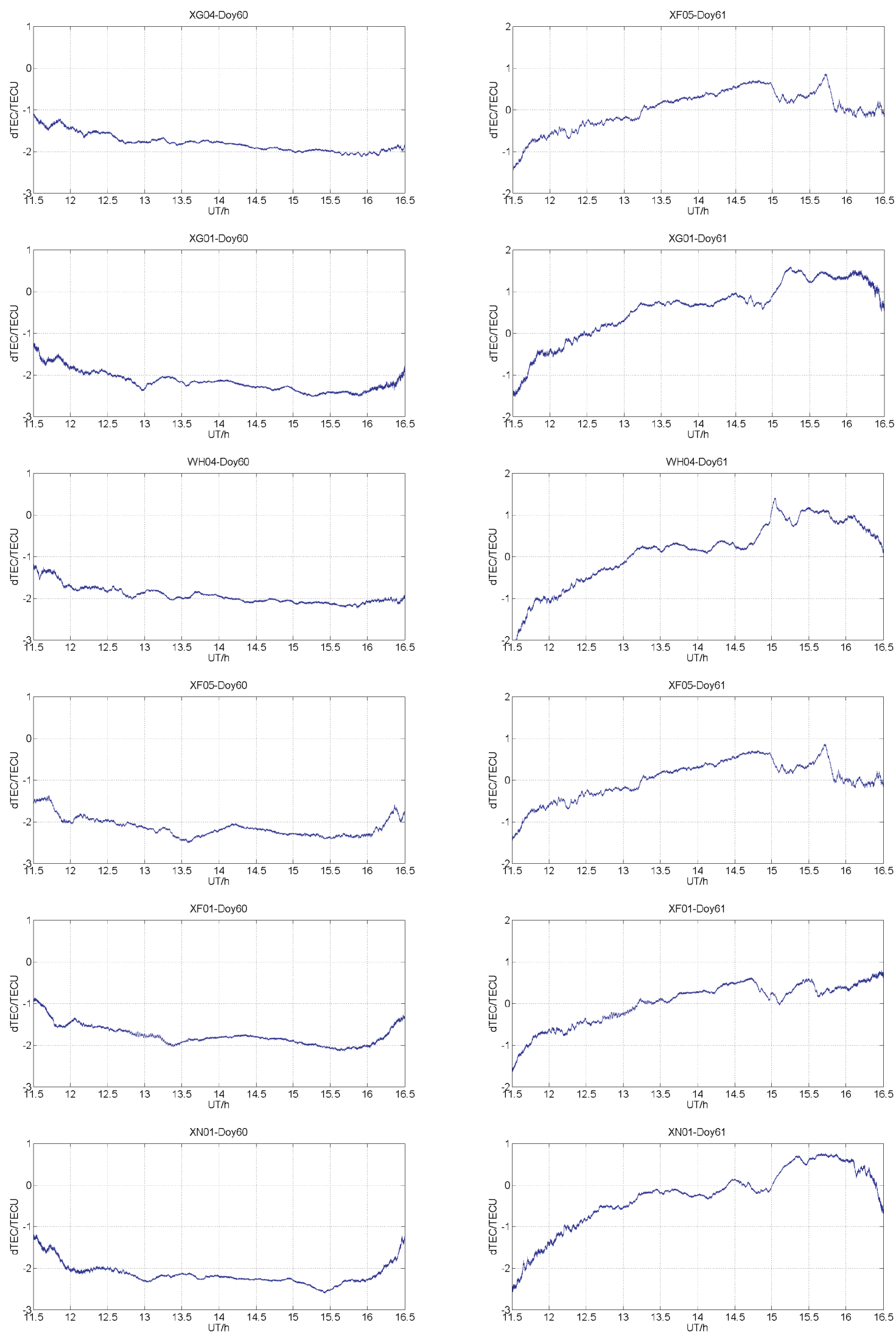

Figure 9. Detecting ionospheric disturbances series by One-week average difference technique over the six stations, (left) differences of the day before the event day, (right) differences of the event day. 


\section{Mohamed Freeshah et al.}

In this paper, the present results can confirm the ionospheric disturbance was observed in the TEC through three methods, the mechanism responsible for these disturbances above the strong thunderstorms in Wuhan could be the generated electric fields from lightning and convective AGWs produced by thunderstorms.

It is unfortunate we lack information about simultaneous ionosonde observation associated with the lightning in our data. Subsequently, since STEC derived from GNSS observation is only total electron content along the path from station to satellite, it is not easy to determine accurately the height of the occurrence of ionospheric disturbance resulting from a lightning strike.

Yue et al., [2016] have concluded that the ionospheric disturbance is mostly observed in the E and F region based on combined GNSS rays from LEO-based GNSS and the ground-based receivers to get good global resolution in the topside ionosphere during a geomagnetic storm. As the F region is located too high to be associated with lightning, meanwhile, it is worthy of indicating that the ionospheric perturbations were preceding revealed in the ionospheric Es region. In 2005, Davis and Johnson have concluded that electrical discharge is likely responsible for any ionospheric enhancement and the lightning is concerned with the disturbance ionospheric Es layer which represented as the localized enhancement of electron density [Davis and Johnson, 2005]. A dominant response after few hours of lightning has existed. It was a result of GWs generated by the thunderstorm which has a large vertical wavelength. However, the waves' vertical component is small compared with their horizontal velocity [Chimonas, 1971; Johnson and Davis, 2006]. In 2008, Davis and Lo have investigated the response to lightning strokes in the ionospheric Es layer by a superposed epoch study. It has been revealed that the dominant cause of the observed ionospheric disturbance in the sporadic layer was related to cloud-to-ground lightning [Davis and Lo, 2008]. Although [Johnson and Davis, 2006] have discussed the potential mechanisms summarized by [Rycroft, 2006] in relation to the enhancement of the Es layer at 100 $\mathrm{km}$ is associated with sprites. While [Davis and Lo, 2008] suggested that this unlikely whereas their results were lack to the peak current which accompanying the lightning. Recently, [Yu et al., 2017] have followed the conclusion by [Inan et al., 1996] which indicated that the local ionosphere can be effected by lightning over a distance of up to $150 \mathrm{~km}$ to study the connection between neutral metal Na layer and thunderstorms.

The few minutes difference between disturbance for the aforementioned CORS stations may be due to their different locations where the geographic location of lightning affect the influence of thunderstorms on the ionosphere. [Chimonas, 1971] was expected the formation of the lower and higher Es layers depend on the Eastwest gravity waves and northerly waves, respectively. In 2006, Johnson and Davis have extended the limits of the data set, used by them in 2005, to $400 \mathrm{~km}$ from Chilton where it was revealed a direct effect of the lightning on the ionosphere beyond the previous limits $(200 \mathrm{~km})$. In addition, the enhancement in the Es layer revealed not only related to the location geographic of lightning but also the position of lightning as well such as cloud-to-ground or inter-cloud lightning [Davis and Lo, 2008].

\section{Conclusions}

The influence of lightning and their thunderstorms could transfer to the high atmosphere so, it is a good way to understand the upper atmosphere coupling by detecting the response of the ionosphere to this phenomenon. In this study, we investigated the ionospheric response by using ground-based GNSS observations from dense CORS during strong thunderstorms over Wuhan city. Before estimating STEC from GPS observations, the TurboEdit algorithm was used to detect cycle slips, correct cycle slips wherever possible and delete data outliers [Blewitt, 1990]. The STEC was derived from the dual-frequency GPS observation from HBCORS. The code-delay and Dual-frequency carrier phase were combined to obtain ionospheric observables represented as the STEC along the LoS between satellite and receiver. Assuming STEC still contains a constant bias after calibrating it [Zhang and Tang, 2015], the STEC were checked to find the possible ionospheric disturbances with respect to maxima and minima values to check the periods of extreme disturbance and first arriving of lightning influence on the ionosphere. The research has found that the ionospheric disturbances have different velocities based on thunderstorm activities. Based on the distance and direction of each CORS station from Wuhan city center. The assessment part was conducted by three methods of Detrended Fluctuations Analysis: (1) Multi-step numerical difference, (2) $6^{\text {th }}$ order polynomials fitting, (3) One-week average difference and was compared with STEC disturbances. The three techniques which were applied in this study represented a fundamental and substantial 
mechanism in the detrended dataset during strong thunderstorms. Applying only one method have some defects, so we used different methods to avoid these defects as possible. Thereby, this issue is very worthy of discussing because maybe misleading results could do dissipation or impediment in detecting the ionospheric fluctuations depending upon the applied detrending technique. On the other hand, considering one day as a reference for subtracting from the day of phenomenon maybe be not enough for the detectable ionospheric TEC disturbances, where it depends mostly upon the latitude of the study area, especially in low latitude regions where ionospheric variability is more dynamic and complex as compared to mid-latitudes [Maruyama et al., 2007]. The analyzed results for the three detrending methods showed that the MSND method has the lowest performance. Meanwhile, the fitted TEC data with $6^{\text {th }}$ order polynomials technique presented an improvement and a discrepancy related to the MSND method. The AD method has satisfied the best performance comparing with TEC disturbances. Based on results of the three detrending methods, further studies are therefore necessary to evaluate more ways with different phenomena, investigating various case studies for the further improvement could lead to a fast and efficient algorithm for detecting of duration and frequency of ionospheric perturbations can be proposed, where it will be more suitable for certain phenomena and regions.

Funding. This research was funded by the National Science Fund for Distinguished Young Scholars (no. 41825009), the National Natural Science Foundation of China (no. 41904026), the Hubei Province Natural Science Foundation of China (no. 2018CFA081).

Acknowledgments. We are very grateful to HBCORS for providing GNSS data. The numerical calculations have been done on the supercomputing system in the Supercomputing Center of Wuhan University. We are very grateful to the Crustal Dynamics Data Information System (CDDIS) data center for providing observation data and navigation file by the following FTP server: ftp://cddis.gsfc.nasa.gov/pub/gps/data/daily/ and the observation data from a geodetic survey of Hubei CORS (restricted). In addition, the Dst index, Kp index and F10.7 index are from National Aeronautics and Space Administration (NASA) with following: https://omniweb.gsfc.nasa.gov/form/dx1.html. We would also like to express our gratitude to Dr. Xiaodong Ren for his help in reviewing the article. The authors thank for the valuable comments of the reviewers and their promising suggestions to improve this paper.

\section{References}

Amieri-Simkooei, A. R., and J. Asgari (2012). Harmonic analysis of total electron contents time series: methodology and results, GPS Solutions, 16(1), 77-88.

Amin, M. M. (2015). Influence of lightning on total electron content in the ionosphere using WWLLN lightning data and GPS data. University of Cape Town, South Africa.

Barta, V., C. Scotto, M. Pietrella, V. Sgrigna, L. Conti and G. S'atori (2013). A statistical analysis on the relationship between thunderstorms and the sporadic E Layer over Rome, Astronomical Notes, 334(9), 968-971.

Blanc, E. (1985). Observations in the upper atmosphere of infrasonic waves from natural or artificial sources: A summary, Ann. Geophys., 3(6), 673-687.

Blewitt, G. (1990). An automatic editing algorithm for Gps data, Geophys. Res. Lett., 17(3), 199-202.

Burrell, A. G., N. A. Bonito, and C. S. Carrano (2009). Total electron content processing from GPS observations to facilitate ionospheric modeling, GPS Solutions, 13(2), 83-95.

Calais, E., and J. B. Minster (1995). GPS detection of ionospheric perturbations following the January 17, 1994, Northridge Earthquake, Geophys. Res. Lett., 22(9), 1045-1048.

Cheng, Z., S. A. Cummer, H. Su and R. Hsu (2007). Broadband very low frequency measurement of D region ionospheric perturbations caused by lightning electromagnetic pulses, J. Geophys. Res.: Space Physics, 112(A6).

Chimonas, G. (1971). Enhancement of sporadic E by horizontal transport within the layer, J. Geophys. Res.: Space Physics, 76(19), 4578-4586. 


\section{Mohamed Freeshah et al.}

Ciraolo, L., F. Azpilicueta, C. Brunini, A. Meza and S. M. Radicella (2007). Calibration errors on experimental slant total electron content (TEC) determined with GPS, J. Geod., 81(2), 111-120.

Davis, C. J., and C. G. Johnson (2005). Lightning-induced intensification of the ionospheric sporadic E layer, Nature, 435, 799-801.

Davis, C. J. and K. Lo (2008). An enhancement of the ionospheric sporadic-E layer in response to negative polarity cloud-to-ground lightning, Geophys. Res. Lett., 35(5).

Deng, Z., F. Zus, S. Heise, J. Wickert and H. Schuh (2016). Global ionosphere product based on new mapping function, IGS Workshop, 08-12 Feb. 2016, Sydney, NSW, Australia.

He, B., Z. Wei and C. Gao (2011). Reflection on the operation and management mechanism of HBCORS, Geospatial Info., 9(2), 6-12.

Hernandez-Pajares, M., J. M. Juan and J. Sanz (2006). Medium-scale traveling ionospheric disturbances affecting GPS measurements : Spatial and temporal analysis, J. Geophys. Res. Space Physics, 111(A7), https://doi.org/10.1029/2005JA011474

Inan, U. S., W. A. Sampson and Y. N. Taranenko (1996). Space-time structure of optical flashes and ionization changes produced by lighting-EMP, Geophys. Res. Lett., 23(2), 133-136.

Jain, S., S. K. Vijay and A. K. Gwal (1996). An empirical model for IEC over Lunping, Adv Space Res, 18(6), $263-$ 266.

Johnson, C. G. and C. J. Davis (2006). The location of lightning affecting the ionospheric sporadic-E layer as evidence for multiple enhancement mechanisms, Geophys. Res. Lett., 33(7), https://doi.org/10.1029/2005GL025294.

Lay, E. H., X. Shao and C. S. Carrano (2013). Variation in total electron content above large thunderstorms, Geophys. Res. Lett., 40(10), 1945-1949.

Lay, E. H. and X. M. Shao (2011). Multi-station probing of thunderstorm-generated D-layer fluctuations by using time-domain lightning waveforms, Geophys. Res. Lett., 38(23), https://doi.org/10.1029/2011GL049790.

John F. Kennedy Space Center, NASA (2006). Lightning and the Space Program-NASA Facts, NASA, Merritt Island, Florida, USA.

Liu, Y. and S. Jin (2019). Ionospheric Rayleigh Wave Disturbances Following the 2018 Alaska Earthquake from GPS Observations, Remote Sensing, 11(8), 901.

Lu, G. (2006). Transient electric field at high altitudes due to lightning : Possible role of induction field in the formation of elves, J. Geophys. Res. Space Physics, 111(D2), https://doi.org/10.1029/2005JD005781.

Mannucci, A. J., B. D. Wilson, D. N. Yuan, C. H. Ho, U. J. Lindqwister and T. F. Runge (1998). A global mapping technique for GPSderived ionospheric total electron content measurements, Radio Science, 33(3), 565-582.

Maruyama, T., M. Kawamura, S. Saito, K. Nozaki, H. Kato, N. Hemmakorn, T. Boonchuk, T. Komolmis, and C. H. Duyen (2007). Low latitude ionosphere-thermosphere dynamics studies with inosonde chain in Southeast Asia, Ann. Geophys., 25, 1569-1577.

Nie, Z., Y. Huang, G. Liu and Z. Jia (2013). Quality evolution of data from CORS in Hubei, Journal of Geodesy and Geodynamics, 33(6), 53-61.

Park, J., R. R. B. Von Frese, D. A. Grejner-Brzezinska, Y. Morton and L. R. Gaya-Pique (2011). Ionospheric detection of the 25 May 2009 North Korean underground nuclear test, Geophys. Res. Lett, 38(22).

Pasko, V. P., U. S. Inan, T. F. Bell and Y. N. Taranenko (1997). Sprites produced by quasi-electrostatic ionization in the lower ionosphere, J. Geophys. Res. Space Physics, 102(A3), 4529-4561.

Rama Rao, P. V. S., K. Niranjan and D. S. V. V. D. Prasad, S. Gopi Krishna and G. Uma (2006). On the validity of the ionospheric pierce point ( IPP ) altitude of $350 \mathrm{~km}$ in the Indian equatorial and low-latitude sector, Ann. Geophys., 24, 2159-2168.

Rycroft, M. J. (2006). Electrical processes coupling the atmosphere and ionosphere: An overview, J. Atmos. Sol.Terr. Phys., 68(3-5), 445-456.

Mende, S. B., H. U. Frey, R. R. Hsu, H. T. Su, A. B. Chen, L. C. Lee, D. D. Sentman, Y. Takahashi and H. Fukunishi. (2005). D region ionization by lightning-induced electromagnetic pulses, J. Geophys. Res. Space Physics, 110(A11), https://doi.org/10.1029/2005JA011064.

Salem, M. A., N. Liu and H. K. Rassoul (2015). Effects of small thundercloud electrostatic fields on the ionospheric density profile, Geophys. Res. Lett., 42(6), 1619-1625.

Savastano, G., A. Komjathy, O. Verkhoglyadova, A. Mazzoni, M. Crespi, Y. Wei and A. J. Mannucci (2017). Real- 
time detection of tsunami ionospheric disturbances with a stand-alone GNSS receiver: A preliminary feasibility demonstration, Sci. Rep., 7, 46607.

Schaer, S. (1999). Mapping and predicting the Earth's ionosphere using the Global Positioning System. Univ. Bern, Bern, Switzerland.

Sentman, D. D., E. M. Wescott, R. H. Picard, J. R. Winick, H. C. Stenbaek-Nielsen, E. M. Dewan, ... J. Morrill (2003). Simultaneous observations of mesospheric gravity waves and sprites generated by a midwestern thunderstorm, J. Atmos. Sol. Terr. Phys., 65(5), 537-550.

Taylor, M. J., and M. A. Hapgood (1988). Identification of a thunderstorm as a source of short period gravity waves in the upper atmospheric nightglow emissions, Planet. Space Sci., 36(10), 975-985.

Ugur, C., and S. Ibrahim (2013). Mathematical Physics - Proceedings of The 13th Regional Conference, Singapore: World Scientific Publishing Co. Ltd.

Yu, B., X. Xue, G. Lu, M. Ma, X. Dou, X. Qie, B. Ning, L. Hu, J. Wu,Y. Chi (2015). Evidence for lightning-associated enhancement of the ionospheric sporadic e layer dependent on lightning stroke energy, J. Geophys. Res. Space Physics, 120(10), 9202-9212.

Yu, Bingkun, X. Xue, C. Kuo, G. Lu, C. J. Scott, J. Wu, J. Ma, X. Dou, Q. Gao, B. Ning, L. Hu, G. Wang, M. Jia, C. Yu, X. Qie (2019). The intensification of metallic layered phenomena above thunderstorms through the modulation of atmospheric tides, Sci. Rep., 9, 17907.

Yu, Bingkun, X. Xue, G. Lu, C. Kuo, X. Dou, Q. Gao, ... Y. Tang (2017). The Enhancement of Neutral Metal Na Layer Above Thunderstorms, Geophys. Res. Lett., 44, 9555-9563.

Yue, J., and W. A. Lyons (2015). Structured elves: Modulation by convectively generated gravity waves, Geophys. Res. Lett., 42, 1004-1011.

Yue, X., W. Wang, J. Lei, A. Burns, Y. Zhang, W. Wan, L. Liu, L. Hu, B. Zhao, W. Schreiner (2016). Long-lasting negative ionospheric storm effects in low and middle latitudes during the recovery phase of the 17 March 2013 geomagnetic storm, J. Geophys. Res. Space Physics, 121, 9234-9249.

Zhang, C., C. Feng and Z. Zhang (2013). Application of CORS System in Fixed Section Measurement of Yangtze River in Hubei, Geomatics and Spatial Information Technology, 36(10), 124-126.

Zhang, Q. and Q. Zhao (2019). Analysis of the data processing strategies of spherical harmonic expansion model on global ionosphere mapping for moderate solar activity, Adv. Space Res., 63(3), 1214-1226.

Zhang, X. and L. Tang (2015). Traveling ionospheric disturbances triggered by the 2009 North Korean underground nuclear explosion, Ann. Geophys., 33(1), 137-142.

Zhang, X. and L. Tang (2015). Detection of ionospheric disturbances driven by the 2014 Chile tsunami using GPS total electron content in New Zealand, J. Geophys. Res. Space Physics, 120, 1-8.

Zhang, Y., H. Yang, S. Zhang, J. Li and H. Chen (2013). Discussion on provincial CORS networking based on HBCORS. Science of Surveying and Mapping, 38(6), 88-90.

Zolesi, B. and L. R. Cander (2014). Ionospheric Prediction and Forecasting. Verlag Berlin Heidelberg: Springer.

*CORRESPONDING AUTHOR: Xiaohong ZHANG,

School of Geodesy and Geomatics, Wuhan University,

129 Luoyu Road, Wuhan 430079, China and

Key Laboratory of Geospace Environment and Geodesy, Ministry of Education,

129 Luoyu Road, Wuhan 430079, China and

Collaborative Innovation Center for Geospatial Technology,

129 Luoyu Road, Wuhan 430079, China,

e-mail:xhzhang@sgg.whu.edu.cn

(c) 2020 the Istituto Nazionale di Geofisica e Vulcanologia.

All rights reserved 